\title{
Geoethics and philosophy of Earth sciences: the role of geophysical factors in human evolution
}

\author{
Telmo Pievani
}

Università di Milano-Bicocca, Dipartimento di Scienze Umane per la Formazione, Milano, Italy

\author{
Article history \\ Received December 20, 2011; accepted February 21, 2012. \\ Subject classification: \\ Geoethics, Philosophy of Earth sciences, Scientific prediction, Risk, Natural disasters, Probability.
}

\begin{abstract}
This article explores the role of philosophy of the Earth sciences in the foundation of the principles of 'geoethics'. In particular, the focus is on two different examples of philosophical analysis in the field of geosciences: the first is the trial against the Italian National Commission for Forecasting and Predicting Great Risks, which was charged with negligence in communication and prediction on the occasion of the earthquake that almost destroyed the city of L'Aquila on the night of April 6, 2009; the second is related to the scientific and theoretical consequences of the updated geographical scenario of the human global populating of the Earth, based on archeological, paleontological and genetic data. Our concept of 'scientific prediction' in the case of geophysical phenomena and the new ways to see human evolution that depend on geophysical factors have ethical and philosophical implications that are crucial for the foundations of geoethics. The tentative conclusion is that we need an evolutionary sense of belonging to our Planet, and a concept of 'natural' phenomena and 'natural' disasters that should not be an alibi for the underestimation of our political and ethical responsibilities.
\end{abstract}

\section{Introduction}

To date, philosophers of science have paid insufficient attention to the Earth sciences. However, crucial epistemological issues deserve to be tackled through the analysis of these fields of research that are intended as 'special sciences'. Among others, these issues include: the extent to which these disciplines and their principles can be reduced to apparently more fundamental ones, like physics; the role of past events (and so not observable) in their explanations, theories and descriptions that are devoted to the reconstruction of historical and contingent processes through law-like patterns and generalizations that are considered as nonuniversal but context dependent; the need for a plurality of methodologies of explanation, which will be causal and mechanistic in some cases, narrative and historical in other cases, and with various mixes of these two [Frodeman 1995, Cleland 2001, Kleinhans et al. 2005]; and the structures of geological 'deep time' (e.g. circular, linear, progressive) that emerge from the Earth sciences [Gould 1987].

These philosophical lines of analysis, with the results shared at the moment among the community of scholars, are very similar to those discussed in another young field in the philosophy of science: the philosophy of biology, and particularly, the philosophy of evolutionary biology [Sterelny 1996]. The influence of local circumstances (under-determined by the data), contingent events, and unpredictable nonlinear processes, together with the search for general regularities, appear to be the main link of resemblance between the two domains [Sterelny and Griffiths 1999], in a welcome global vision of life sciences and Earth sciences.

In this perspective, it must be remembered that Charles R. Darwin's first training as a naturalist was in geology, a discipline that was intended by him to be a model of methodology (due to its ability to show global patterns of change) and a conceptual framework for evolutionary gradualism [Herbert 2005, Pievani 2009]. In his youth and his notebooks, we can clearly see that Darwin was actually the heir who extended the geological revolution to the life sciences, through Charles Lyell's uniformitarianism and actualism. Since his first notes during the voyage of the Beagle, the geological instability of the Earth surface was the culture medium of Darwin's transmutational view of life, as he emerging from a peculiar mix of fossil evidence and biogeographical observations. So, the history of the biosphere and the history of the physical planet have a lot in common, not only in their scientific explanations, but also in their philosophical interpretations and historical roots.

\section{Predictions in Earth sciences: from philosophy of science to 'geoethics'}

A recent Italian example illustrates the need for a philosophical and methodological evaluation of the Earth sciences and the nature of their explanations. The gov- 
ernmental National Commission, composed of six leading Earth scientists and experts involved in the public discussion and security policies for the prevention of damage from earthquakes in Italy (the National Commission for Forecasting and Predicting Great Risks), is on trial, with the serious imputation of multiple manslaughter. This is because of the reassuring statements that were disseminated during the seismic swarm of the low-level tremors and the inability to predict the catastrophic earthquake of April 6, 2009, in the city of L'Aquila and its surroundings. The position of the scientists is paradoxical, because in the case of a dramatic and generalized warning to the population with every seismic swarm, in the absence of the subsequent earthquake (like in the majority of historically reported cases), they might have been charged with the opposite accusation, of instigating a false alarm and panic. Clearly, in this case, we are dealing with the concept of 'prediction' in general science, and particularly in Earth sciences, and how to communicate it.

Following the accusations, it is supposed that the scientists should have foreseen the specific occurrence or the exact probability of an earthquake (clearly impossible with our current technologies), or that they would have alerted the population in every similar case (unrealistic for earthquakes like that in L'Aquila). Probably the style of communication of the Commission was truly incomplete and contradictory, mostly with the idea that repeated tremors would mean less probability of a major earthquake. The misleading communication was driven by the political and contingent demand for calming news, and the issue here is the way of communicating scientific evidence based on probability and degrees of risks, and not on certainties, as Stephen S. Hall pointed out in Nature in September 2011 [Hall 2011]. Nevertheless, it appears that an overestimated interpretation of the concept of 'scientific prediction' might become a way to underestimate, at least in public debate, the political, social and ethical responsibility for the heavy human and civil damage produced by a not so infrequent seismic event in the Apennine region.

However, in terms of the philosophy of science, the case has another interesting side: due to their robust and appreciated tradition of research, Italian Earth scientists have actually made a lot of specific 'predictions', and have even visualized the micro-zones of statistical seismic risk for the whole Italian territory, and they have worked for decades on detailed recommendations for institutions and people living in highly seismic regions in Italy. Furthermore, the occurrence of an earthquake or a prolonged seismic activity in areas with previous low probabilities, like in EmiliaRomagna region in northern Italy since May 2012, shows the evolving and historic features of these maps of risk. The difficulties in the evaluation of the real risk through the analysis of seismic precursory symptoms have to be handled in a probabilistic way. However, probability, which is so crucial in our most advanced scientific models, is one of the less understood concept in public debates. This is exactly the point: these are probabilistic predictions of risks, and not of specific events (like in a prophecy). Recommendations and probabilistic risks claim for consequent long-term political actions of preventive measures and for the general education and ethics of prevention. Even the most advanced calculations of the fragility of buildings and hazard probabilities are useless, even when frequently updated, without consolidated practices of prevention.

What is under discussion here is not only the difficult task of communicating risks and probabilities, but the relationships between human populations and their territories. So, in such cases, a rigorous philosophical and methodological analysis might be extremely useful, and also in public debates and trials, for addressing the concepts and terms we use in the Earth sciences, and for the correct foundation of ethical arguments related to our knowledge of the mechanisms and processes of the Earth.

\section{Sons of an unstable Earth}

The same argument, from the philosophy of Earth sciences to geoethics, can be outlined for the proposal of more general ethical values related to, and coming from, the geosciences. Take the case of the most updated evidence about human evolution. Our journey as humans started two million years ago, when the first specimens of the Homo genus walked out of the African continent and colonized Eurasia. A long time after that, small groups belonging to our species, Homo sapiens, once again moved from Africa and launched into the exploration of the old and new worlds. The journey is still not over: human beings have crossed or settled in every corner of the land above water. That handful of pioneers has now resulted in a population of seven billion people.

Until a few thousand years ago, the Earth was populated by several human species, of which there were at least five [Tattersall 2009, Wood and Harrison 2011]. Now we have ended up with just one. The history of the many humans at the beginning has been shrouded in darkness for a long time, due to a lack of scientific and historical evidence. Now, due to the knowledge of paleontologists, archeologists and geneticists, we can retrace the paths of the first explorers, and through them the great journey into human diversity, through genes, peoples and languages [Cavalli-Sforza et al. 1994].

In this field, we discover that geophysical factors were crucial for our evolution and diversification, which started with the role of the Great Rift Valley for the separation of the first hominin species in the eastern parts of the continent, which were progressively more arid. Later, where 
once there were lakes, rivers and green grassland, now we have the expanse of the Sahara Desert; other humans saw what we can no longer see. Continental drift, volcanic eruptions, environmental instability, climate change, and fragmentation of habitats have all radically shaped the evolutionary path for us, as for all species. All of the major events for our genus took place in the midst of the unstable Pleistocene climate that started more than two million years ago, and then again one million years ago with the glacial and interglacial periods, the rising and falling of the sea levels, the coming and going of geographical barriers, islands turning into peninsulas, and vice-versa, lands locked in by ice, areas of vegetation shifting latitude, and with them the herbivores and carnivores.

The movements of Homo in and out of Africa were largely due to the alternating dry and wet or damp phases in the Sahara and the Sahel. These areas were green and fertile expanses with waterways running across them that are now only visible from satellites [Osborne et al. 2008]. They attracted hominins from the South and the East, who were then driven in all directions, including North and North-East, when the desertification progressed. Oscillations were in turn caused by variations in the intensity of the system of Atlantic Ocean currents [Castañeda et al. 2009]. This was particularly true after the closure of the Isthmus of Panama. So, who would have thought that something so deep would bond us humans to the Sahara, to the continental drift, and to our ability to adapt culturally and biologically to the whims of a living planet.

Eight thousand generations ago (or about 200 thousand years ago) the first Homo sapiens made their appearance in sub-Saharan Africa, during the dry phase that coincided with the Quaternary Ice Age. It was a small population with some identifying traits, such as a tall and slim build, a large skull and cranial capacity (exceeding 1400 $\mathrm{cm}^{3}$ ), good stone working skills, and different modulation of gene expression that regulated development and growth. Homo sapiens spread throughout Africa, and then probably left the continent in several waves, following the shorelines and congenial climate zones, colonizing Eurasia and then Australia and the Americas [Cavalli Sforza and Cavalli Sforza 1995].

Between 60,000 and 50,000 years ago, the islands of the Indonesian archipelago formed an uninterrupted land bridge up to Bali, called Sunda. However, to reach the Australian supercontinent (Australia, New Guinea and Tasmania were all one) a $70 \mathrm{~km}$ to $100 \mathrm{~km}$ channel had to be forded or sailed to pass Timor or Sulawesi. At such a distance, it is difficult to see the other shore. Some Homo sapiens tribes forded the sea stretch and were successful, probably more than 55,000 to 50,000 years ago. Elsewhere, in the glacial phases, a land bridge of at least $2,000 \mathrm{~km}$ joined also what is now Alaska to the Chukchi. It was the
Beringia continent that has now disappeared. This was wild and wind beaten, and populated by woolly mammoths, and it is currently mostly submerged, with the remains of its ancient dwellers. It might have been 25,000 years ago when the Siberian hunters crossed Beringia and settled there, then moved on in pursuit of the mammoth and caribou herds, and descended into the great plains of North America.

In this new geographical scenario of global peopling and diversification of human groups [Cavalli Sforza and Pievani 2011], we discover that on several occasions we were very lucky from a geophysical point of view. Molecular data show a drop in Homo sapiens numbers around 70,000 to 75,000 years ago, which coincided with a drop in world temperatures, maybe due to the volcanic winter caused by the catastrophic eruption of Toba on the Isle of Sumatra. This was a global environmental disaster, equivalent to many eruptions of Krakatoa all together. We had apparently ended up in what evolutionists call an 'evolutionary bottleneck': a drastic reduction in population numbers that led us to the brink of extinction. Then the few survivors starting up again after the cataclysm, with a reduced internal genetic diversity.

It might have been just a coincidence time-wise, but the limited genetic variation of present-day humans suggests that the founding group was rather small, and that later the human population had to overcome a number of bottlenecks due to environmental crises [Huff et al. 2010]. Other experts believe that the bottleneck (or one of them) took place earlier in Africa, during the Ice Age that lasted from 190,000 to 123,000 years. Due to the changes in the winds and rainfall, glaciation led to increased arid zones in Africa. The few Homo sapiens may have found refuge on the more welcoming coastlines of the Cape in South Africa, or at the southern tip of the Rift Valley. Whatever happened, it is clear that our evolution, and even our genetic diversity, were shaped by geophysical global phenomena and geographical constraints, which has been underestimated in evolutionary models to date. The weak but intelligible molecular traces of this history are still present. We see maximal genetic diversity in African huntergatherer populations, with a peak in southern Africa [Henn et al. 2011], and a general decrease in genetic diversity with the distance from Africa [Ramachandran et al. 2005]. This is a picture of human genetic variation that is coherent with a process of 'serial founder effects' from Africa [Romero et al. 2009, Li et al. 2008].

The same role of geophysical factors is valid for the Neolithic revolution and for recent times. The domestication of plants and animals began between 12,000 and 7,000 years ago, after the end of the great cold in the last Ice Age. With agriculture and animal domestication, the ecosystems spontaneously started producing much more than they 
had done previously. The increase in numbers led to new movement and dispersion of populations, and hybridizations and conflicts. Human populations began increasing at an unprecedented rate, with the development of stable settlements and giving rise to the first urban centers in the course of the millennia. So, the interplay between environmental and geophysical determinants, historical contingencies, and cultural diversities is now a keystone for our understanding of the natural history of the human species and human societies [Munoz et al. 2010, Diamond and Robinson 2010].

As in the case of mass-extinctions produced by global geophysical events in long-term evolution, the timing of our young history as a species was punctuated by major geophysical events. We are the sons of the geophysical and ecological instability of our Planet, which produced major macro-evolutionary patterns of biological change [Eldredge 1999].

\section{Geoethics and our ideas of 'Nature'}

As causes of change, geophysical factors and geographical constraints are independent from adaptive micro-evolutionary dynamics of change in genetic frequencies, although they can influence these from higher levels of evolution, shaping, for example, the population structure of a species in its territory. This means first that we need an extended and multilevel theory of evolution, with a Neo-Darwinian core and a surrounding plurality of new patterns of transformation [Okasha 2006, Pievani 2012]. However, it also means that the macro-evolution of the several human species was the history of their relationships with geophysical phenomena and contingent events. We were not alone in our history of species, and we were not expected as the 'mainstream' of human evolution [Pievani 2011]. From a philosophical point of view, this discovery means that we need more evolutionary 'humility' and a stronger feeling of belonging to our Planet.

The expressions of violence and unpredictability of natural phenomena that shock our societies so much today are the normal ecological niches where we were born. We would not be here at this moment without them. So, in what sense do we say that a tsunami, an earthquake, a volcanic eruption, or a hurricane are 'natural' disasters? The catastrophic effects of these phenomena, as their usual geophysical power or strengthened by anthropically forced climate change, are measured by the disruption of human artefacts and settlements, and by the consequent loss of human lives. So, if we build a little village under a slope subject to landslips, or we regiment torrents between cement barriers, or we erect nonearthquake proof buildings in high risk territories, the disaster itself will be completely human, cultural, political, social and ethical, but certainly not 'natural'. The role of geoethics here should be not only the awakening of public opinion to environmental problems, hydro-geological instability, and maintenance of territory, but also a more educated idea of what Nature is (the only opportunity we have for making a living) and is not (an indefinite repository of available resources). Our idealizations of 'Nature', as a harmonic Eden or a wicked nemesis are frequently our preferred alibi for hiding from our responsibilities.

In cases like the trial in L'Aquila, Italy, in the future, we will have to manage problems of risk assessment and public communication about not only known natural disasters like earthquakes and volcanic eruptions, but also unpredictably violent weather events, such as floods and droughts, or hurricanes and tornadoes. Earth scientists have to be careful to communicate their noncertainties in a transparent and authoritative way: geoethics will be more and more an ethics of communication and relationships with the wide audience of science. However, a more general philosophical topic cannot be underestimated in these situations: in what sense do we say that these disasters are 'natural'? From a natural point of view, they are normal geophysical phenomena, given certain circumstances. The responsibility of the disaster is primarily political and social. The negligence in communication, such as that of Mother 'Nature', should not be our alibi.

\section{References}

Castañeda, I.S, S. Mulitza, E. Schefuss, R.A. Lopes dos Santos, J.P. Sinninghe Damsté and S. Schouten (2009). Wet phases in the Sahara/Sahel region and human migrations patterns in North Africa, Proc. Natl. Acad. Ssi. USA, 106, 20159-20163.

Cavalli Sforza, L.L., P. Menozzi and A. Piazza (1994). The History and Geography of Human Genes, Princeton, NJ, USA, Princeton University Press.

Cavalli Sforza, L.L., and F. Cavalli Sforza (1995). The Great Human Diasporas, New York, USA, Addison-Wesley.

Cavalli Sforza, L.L. and T. Pievani (2011). Homo sapiens. La grande storia della diversità umana, Torino, Codice Edizioni.

Cleland, C.F. (2001). Historical science, experimental science, and the scientific method, Geology, 29, 987-990.

Diamond, J., and J.A. Robinson (2010). Natural Experiments of History, Cambridge, MA, USA, Harvard University Press.

Eldredge, N. (1999). The Pattern of Evolution, New York, USA, W.H. Freeman and C.

Frodeman, R. (1995). Geological reasoning: geology as an interpretive and historical science, Geol. Soc. Am. Bull., 107, 960-968.

Gould, S.J. (1987). Time's Arrow, Time's Cycle. Myth and Metaphor in the Discovery of Geological Time, Cambridge, MA, USA, Harvard University Press. 
Hall, S.S. (2011). Scientists on trial: at fault?, Nature, 477, 264-269.

Henn, B.M., C.R. Gignoux, M. Jobin, J.M. Granka, J.M. Macpherson, J.M. Kidd, L. Rodríguez-Botigué, S. Ramachandran, L. Hon, A. Brisbin, A.A. Lin, P.A. Underhill, D. Comas, K.K. Kidd, P.J. Norman, P. Parham, C.D. Bustamante, J.L. Mountain and M.W. Feldman (2011). Hunter-gatherer genomic diversity suggests a southern African origin for modern humans, Proc. Natl. Acad. Sci. USA, 108 (13), 5154-5162.

Herbert, S. (2005). Charles Darwin, Geologist, Ithaca, NY, USA, Cornell University Press.

Huff, C.D., J. Xing, A.R. Rogers, D. Witherspoon and L.B. Jorde (2010). Mobile elements reveal small population size in the ancient ancestors of Homo sapiens, Proc. Natl. Acad. Sci. USA, 107, 2147-2152.

Kleinhans, M.G., C.J.J. Buskes and H.W. de Regt (2005). Terra Incognita: Explanation and Reduction in Earth Sciences, Intl. Stud. Philos. Sci., 19, 289-317.

Li, J.Z., D.M. Absher, H. Tang, A.M. Southwick, A.M. Casto, S. Ramachandran, H.M. Cann, G.S. Barsh, M.W. Feldman, L.L. Cavalli Sforza and R.M. Myers (2008). Worldwide human relationships inferred from genomewide patterns of variations, Science, 319, 1100-1104.

Munoz, S.E., K. Gajewski and M.C. Peros (2010). Synchronous environmental and cultural change in the prehistory of the northeastern United States, Proc. Natl. Acad. Sci. USA, 107, 22008-22013.

Okasha, S. (2006). Evolution and the Levels of Selection, Oxford, UK, Clarendon Press.

Osborne, A.H., D. Vance, E.J. Rohling, N. Barton, M. Rogerson and N. Fello (2008). A humid corridor across the Sahara for the migration of early modern humans out of Africa 120,000 years ago, Proc. Natl. Acad. Sci. USA, 105, 16444-16447.

Pievani, T. (2009). The World after Charles R. Darwin: Continuity, Unity in Diversity, Contingency, In: Rend. Fis. Acc. Lincei, Springer, 20, 355-361.

Pievani, T. (2011). La vita inaspettata. Il fascino di un'evoluzione che non ci aveva previsto, Milano, Raffaello Cortina Editore.

Pievani, T. (2012). An Evolving Research Programme: the Structure of Evolutionary Theory from a Lakatosian Perspective, In: The Theory of Evolution and Its Impact, A. Fasolo (ed.), New York, Springer, 211-228.

Ramachandran, S., O. Deshpande, C.C. Roseman, N.A. Rosenberg, M.W. Feldman and L.L. Cavalli Sforza (2005). Support from the relationship of genetic and geographic distance in human populations for a serial founder effect originating in Africa, Proc. Natl. Acad. Sci. USA, 102, 15942-15947.

Romero, I.G, A. Manica, J. Goudet, L.L. Handley and F. Balloux (2009). How accurate is the current picture of human genetic variation?, Heredity, 102, 120-126.

Sterelny, K. (1996). Explanatory pluralism in evolutionary biology, Biol. Philos., 11, 193-214.

Sterelny, K., and P.E. Griffiths (1999). Sex and Death. An Introduction to Philosophy of Biology, Chicago, USA, The University of Chicago Press.

Tattersall, I. (2009). The Fossil Trail, Oxford, UK/New York, USA, Oxford University Press.

Wood, B., and T. Harrison (2011). The evolutionary context of the first hominins, Nature, 470, 347-352.
Corresponding author: Telmo Pievani, Università di Milano-Bicocca, Dipartimento di Scienze Umane per la Formazione, Milano, Italy; email: telmo.pievani@unimib.it.

(C) 2012 by the Istituto Nazionale di Geofisica e Vulcanologia. All rights reserved. 